\title{
ON THE 50TH BIRTHDAY OF PAVEL G. SERAFIMOVICH
}

\author{
E.I. Kolomiets \\ Samara National Research University, Samara, Russia
}

\begin{abstract}
The article briefly describes the scientific and pedagogical achievements of associate professor, candidate of physical and mathematical sciences Pavel Grigorievich Serafimovich.
\end{abstract}

Keywords: candidate of physical and mathematical sciences, cloud computing, video streams analysis, high-performance computing, diffractive optics, photonic crystals, nanoresonators, nanophotonics.

Citation: Kolomiets E.I. On the 50th Birthday of Pavel G. Serafimovich. CEUR Workshop Proceedings, 2016; 1638: 888-894. DOI: 10.18287/16130073-2016-1638-888-894

\section{Introduction}

On January 21, 2016 candidate of physical and mathematical sciences, senior researcher of the Image Processing Systems Institute of the Russian Academy of Science, and concurrently associate professor of technical cybernetics department of Samara National Research University Pavel Grigorievich Seraphimovich celebrated his fiftieth anniversary. The article briefly describes the scientific and pedagogical achievements of P.G. Serafimovich.

\section{IPSI RAS}

In 1989 P.G. Serafimovich graduated from the faculty of systems engineering of Kuibyshev Aviation Institute (now Samara National Research University) in applied mathematics specialty. After graduation he started working as an engineerprogrammer at the Samara branch of the Central Design Bureau of Unique Instrumentation of the USSR Academy of Sciences, which in 1993 was transformed into Image Processing Systems Institute (IPSI RAS) [1-2]. Since 1993 P.G. Serafimovich has been a junior researcher, since 1994 - a researcher, and since 2002 - a senior researcher of IPSI RAS.

In 1997 he defended his candidate thesis "Analysis of iterative methods for computing phase functions of diffractive optical elements", under the guidance of professor V.V. Kotlyar. In 2016 P.G. Serafimovich submitted to protection his doctoral thesis 
"Computation and modeling of photonic-crystal coupled-resonator optical waveguides", on the specialty 01.04.05 "Optics". Currently P.G. Serafimovich has got 35 Scopus publications, his Hirsch index is 7 .

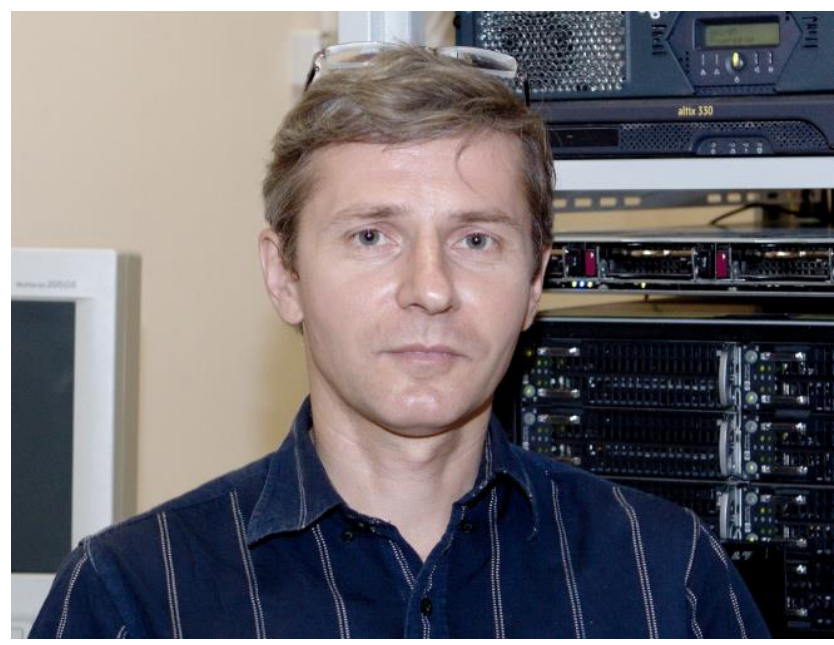

Fig. 1. Pavel Grigorievich Serafimovich

\section{Samara University}

P.G. Serafimovich combines scientific activity with teaching work. Since September, 1995 P.G. Serafimovich has been working part-time at the department of technical cybernetics of Samara University as an associate professor. P.G. Serafimovich reads lectures on courses "Software of Multiprocessor Computer Systems" and "Grid Technologies and Cloud Computing", he conducts practical and laboratory classes in these courses for students studying in the areas of applied mathematics and computer science and of applied mathematics and physics. He also supervises research work of bachelors and masters. Since that time he has prepared a textbook [3].

\section{Main scientific results}

The first scientific results were obtained by P.G. Serafimovich under the guidance of professor V.V. Kotlyar and were focused on iterative methods for calculating diffractive optical elements (DOEs) [4-14]. The developed methods allow to increase the energy efficiency of DOE, at the same time improving the quality of their work. For example, for focusators the methods allow to reduce the mean square deviation of the intensity distribution obtained from the required one. In subsequent years P.G. Serafimovich used the obtained foundation for creating methods of investigating a variety of DOEs in the framework of asymptotic methods and computational experiment [15-20]. 
At the same time P.G. Serafimovich pays great attention to development of software [21-32]. He is involved in creating software products designed to calculate elements of computer optics [21-22], for modeling diffractive nanophotonic devices [25, 26, 31]. At the same time he makes extensive use of the opportunities offered by cloud technologies [25, 26, 31], high-performance and parallel computing technologies [2324]. In these articles he proposed a parallel algorithm for calculating nanophotonic elements that implements the method of Fourier modes. He transformed the computationally intensive algorithm into an intensive algorithm for data processing. The use of the proposed approach on clusters built on the MapReduce technology allows to make efficient use of the intermediate data larger than $1 \mathrm{~TB}$ and to increase significantly the average time between failures of computing cluster nodes (Mean-TimeBetween-Failures (MTBF)).

I would also like to highlight the results he gained in the field of intellectual analysis of video streams $[28,29,32]$ and in development of methods for classifying hyperspectral images $[27,30]$.

From 2002 to 2006 Serafimovich worked in South Korea at the Samsung Advanced Institute of Technology. In this institute he took part in development of several illuminating and laser systems [33, 34], which were patented in the USA [35, 36].

The resulting scientific basis allowed him to start preparing his doctoral thesis. As part of these studies he received a number of interesting results, which are widely published and patented [37-57].

1. He proposed, computed, and numerically investigated a compact integrated onchip nanophotonic element for integration of optical signals [46, 48, 49, 54]. The novelty is that for integration of various orders of optical signals he proposed to use a photonic crystal (PC) nanobeam cavity. This allows to increase compactness of the device dozens of times in comparison with existing analogues. As compared, for example, with ring resonators, large size of the free spectral band $(210 \mathrm{~nm})$ allowed integrating the impulses with width in the range of 150-200 femtoseconds at a wavelength of 1.55 microns with a mean square error of less than $10 \%$.

2. He proposed, computed, and numerically investigated a compact integrated onchip nanophotonic element for differentiation of optical signals [42, 44]. The novelty consists in the fact that he suggested to use a FC nanobeam cavity for optical signals differentiation. The dimensions of the proposed differentiator are $\sim 6,0 \times$ $0,5 \times 0,2$ microns for a wavelength of 1.55 microns. These dimensions are an order less than the existing analogues.

3. He offered, computed, and numerically investigated a compact FC nanobeam cavity having a quality factor above 105 . The novelty is the use of two-components resonator structure [40,51], which allows for the first time to implement a vertical electronic pumping of the resonator.

4. He proposed, computed, and numerically investigated intersecting FC nanobeam cavity with increased mode overlap coefficient $[41,57]$. The novelty consists in using a slit resonance chamber, allowing to increase tens of times the energy density of the electromagnetic field in overlapping area of resonance modes.

5 . He proposed, computed, and numerically explored a compact optical modulator based on a cascade of two FC resonators [53, 56]. The novelty consists in the ability to scale both the amount of pumping energy and the magnitude of spectral shift of the resonance mode. New is also that the proposed modulator allows to imple- 
ment modulation in the field of small (less than $10 \%$ of peak value) intensity of the resonance mode.

6. He proposed, calculated, and numerically explored a compact optical sensor based on a cascade of two FC resonators $[52,55]$. The novelty is the possibility of increasing twice the quality factor of the optical resonance system, thus increasing the sensitivity of the optical sensor.

\section{Conclusion}

In conclusion we would like to wish P.G. Serafimovich to have talented students who would continue and expand his scientific research, and successful defense of his doctoral dissertation!

\section{References}

1. Kolomiets EI. Analysis of the scientific and organizational results of the Image Processing Systems Institute of the RAS. CEUR Workshop Proceedings, 2015; 1490: 309-326. DOI: 10.18287/1613-0073-2015-1490-309-326.

2. Kazanskiy NL. Research \& education center of diffractive optics. Proceedings of SPIE, 2012; 8410: 84100R. DOI: 10.1117/12.923233.

3. Kazanskiy NL, Serafimovich PG, Khonina SN. HPC in the diffraction nanooptics. IPSI RAS, SSAU, Samara, 2010, 119 p. ISBN: 978-5-93673-021-9. [in Russian]

4. Kotlyar VV, Serafimovich PG, Soifer VA. Regularized iterative algorithm for the phase retrieval. Optik, 1993; 94(2): 96-99.

5. Kotlyar VV, Serafimovich PG. Adaptive iterative method of calculating kinoforms. Optics and Spectroscopy, 1994; 77(4): 606-609.

6. Kotlyar VV, Serafimovich PG, Zalyalov OK. Noise-insensitive iterative method for interferogram processing. Optics \& Laser Technology, 1995; 27(4): 251-254.

7. Kotlyar VV, Serafimovich PG, Soifer VA. Weighting iterative method for calculating kinoform. Optics and Spectroscopy, 1995; 78(1): 132-134.

8. Andreev NE, Bychkov SS, Kotlyar VV, Margolin LYa, Pyatnitskiǔ LN, Serafimovich PG. Formation of high-power hollow Bessel light beams. Quantum Electronics, 1996; 26(2): 126-130.

9. Kotlyar VV, Serafimovich PG. Regularization of an iterative phase-correction algorithm for synthetic-aperture radar. Pattern Recognition and Image Analysis, 1996; 6(2): 306-308.

10. Kotlyar VV, Serafimovich PG, Soifer VA. Gradient algorithm for DOE's calculation with constraints on the phase function and regularization. Computer Optics, 1996; 16: 50-53. [in Russian]

11. Kotlyar VV, Serafimovich PG, Soifer VA. An iterative algorithm for designing diffractive optical elements with regularization. Optics and Lasers in Engineering, 1998; 29(4-5): 261-268.

12. Serafimovich PG, Kharitonov SI. The calculation of the field formed by the geometricoptical focusators. Computer Optics, 1998; 18: 96-104. [in Russian]

13. Volotovskii SG, Kazanskii NL, Serafimovich PG, Khonina SN. Modern information technologies in computer optics. Pattern Recognition and Image Analysis: Advances in Mathematical Theory and Applications, 2001; 11(2): 471-472. 
14. Kazanskiy NL, Serafimovich PG, Kharitonov SI. Adaptive iterative algorithm to distinguish different types of waves in acoustic logging data. Computer Optics, 2002; 22: 41-46.

15. Kharitonov SI, Serafimovich PG. The synthesis of wave fields in the framework of electromagnetic theory. Proceedings of the Samara Scientific Center of the Russian Academy of Sciences, 1999; 1(2): 234-240. [in Russian]

16. Kharitonov SI, Serafimovich PG. Asymptotic methods of calculating the fields generated by DOE within the framework of electromagnetic theory. Computer Optics, 1999; 19: 3339. [in Russian]

17. Volotovskii SG, Serafimovich PG, Kharitonov SI. The solution of Maxwell's equations in the space-frequency representation. Computer Optics, 2000; 20: 5-9. [in Russian]

18. Khonina SN, Serafimovich PG, Savel'ev DA, Pustovoř IA. Diffraction at binary microaxicons in the near field. Journal of Optical Technology, 2012; 79(10): 626-631. DOI: 10.1364/JOT.79.000626.

19. Seraphimovich PG. Diffraction analysis of focusing optical elements. Proceedings of SPIE, 2013; 9156: 91560L. DOI: 10.1117/12.2054492.

20. Degtyarev SA. Serafimovich PG. Focused Laser-Beam Scanning by the Apertured Probe of a Near-Field Microscope . Radiophysics and Quantum Electronics, 2015; 57(8-9): 665671.

21. Volotovskiy SG, Golub MA, Doskolovich LL, Kazanskiy NL, Pavelyev VS, Seraphimovich PG, Soifer VA, Kharitonov SI, Tzaregorodzev AYe. Software on computer optics. Computer Optics, 1995; 14-15(2): 94-106. [in Russian]

22. Doskolovich LL, Golub MA, Kazanskiy NL, Khramov AG, Pavelyev VS, Seraphimovich PG, Soifer VA, Volotovskiy SG. Software on diffractive optics and computer generated holograms. Proceedings of SPIE, 1995; 2363: 278-284. DOI: 10.1117/12.199645.

23. Volotovskiy SG, Kazanskiy NL, Seraphimovich PG, Kharitonov SI. A software package for the calculation of diffractive optical elements using high-speed computing means. Computer Optics, 2001; 22: 75-79. [in Russian]

24. Volotovsky SG, Kazanskiy NL, Popov SB, Serafimovich PG. Performance analysis of image parallel processing applications. Computer Optics, 2010; 34(4): 567-572.

25. Kazanskiy NL, Seraphimovich PG. Cloud computing for nanophotonics simulations. Computer Optics, 2011; 35(3): 320-328.

26. Kazanskiy NL, Serafimovich PG. Cloud Computing for Rigorous Coupled-Wave Analysis. Advances in Optical Technologies, 2012; 2012: 398341. DOI: 10.1155/2012/398341.

27. Zimichev EA, Kazanskiy NL, Serafimovich PG. Spectral-spatial classification with kmeans++ particional clustering. Computer Optics, 2014; 38(2): 281-286.

28. Kazanskiy NL, Protsenko VI, Serafimovich PG. Comparison of system performance for streaming data analysis in image processing tasks by sliding window. Computer Optics, 2014; 38(4): 804-810.

29. Protsenko VI, Kazanskiy NL, Serafimovich PG. Real-time analysis of parameters of multiple object detection systems. Computer Optics, 2015; 39(4): 582-591. DOI: 10.18287/0134-2452-2015-39-4-582-591.

30. Kazanskiy NL, Serafimovich PG, Zimichev EA. Spectral-spatial classification of hyperspectral images with k-means++ partitional clustering. Proceedings of SPIE, 2015; 9533 : 95330M. DOI: $10.1117 / 12.2180543$.

31. Kazanskiy NL, Serafimovich PG. Cloud Computing for Nanophotonic Simulations. Lecture Notes in Computer Science, 2013; 7715: 54-67. DOI: 10.1007/978-3-642-38250-5_7.

32. Kazanskiy NL, Protsenko VI, Serafimovich PG. Performance analysis of sliding window filtering of two dimensional signals based on stream data processing systems. Proceedings of SPIE, 2015; 9807: 98070Z.

33. Seraphimovich PG, Ahn PS, Shin JK. Vortex mask design for irregular arrays of contact holes. Proceedings of SPIE, 2004; 5401: 37. DOI: 10.1117/12.556988. 
34. Seraphimovich PG, Cheong BH, Ahn PS, Shin JK, Kim SH. DMD illumination using Diffractive Optical Elements. Digest of Technical Papers - SID International Symposium, 2005; 36(1): 902-905. DOI: 10.1889/1.2036595.

35. Ahn PS, Lee JH, Mun YoK, Cheong BH, Seraphimovich PG. Laser television. US Patent 7,450,186 of May 18, 2005, published of Jan 5, 2006.

36. Seraphimovich PG, Kim SH, Cheong BH, Dho S. Illumination system eliminating laser speckle and projection TV. US Patent 7,746,414 of Sep 13, 2005, published of Jun 29, 2010.

37. Kazanskiy NL, Serafimovich PG, Kharitonov SI. The calculation of the optimum intersection of photonic crystal waveguides by the method of transfer matrix. Proceedings of the Samara Scientific Center of the Russian Academy of Sciences, 2002; 4(2): 300-307. [in Russian]

38. Kazanskiy, N.L., Serafimovich, P.G., Popov, S.B., Khonina, S.N. Using guided-mode resonance to design nano-optical spectral transmission filters. Computer Optics, 2010; 34(2): $162-168$.

39. Kazanskiy NL, Serafimovich PG, Khonina SN. Harnessing the Guided-Mode Resonance to Design Nanooptical Transmission Spectral Filters. Optical Memory and Neural Networks (Information Optics), 2010; 19(4): 318-324. DOI: 10.3103/S1060992X10040090.

40. Kazanskiy NL, Serafimovich PG, Khonina SN. Optical nanoresonator in the ridge of photonic crystal waveguides crossing. Computer Optics, 2011; 35(4): 426-431.

41. Kazanskiy NL, Serafimovich PG, Khonina SN. Enhancement of spatial modal overlap for photonic crystal nanocavities. Computer Optics, 2012; 36(2): 199-204.

42. Kazanskiy NL, Serafimovich PG, Khonina SN. Use of photonic crystal resonators for differentiation of optical impulses in time. Computer Optics, 2012; 36(4): 474-478.

43. Serafimovich PG, Kazanskiy NL, Khonina SN. Two-component cavity based on a regular photonic crystal nanobeam. Applied Optics, 2013; 52(23): 5830-5834. DOI: 10.1364/AO.52.005830.

44. Kazanskiy NL, Serafimovich PG, Khonina SN. Use of photonic crystal cavities for temporal differentiation of optical signals. Optics Letters, 2013; 38(7): 1149-1151. DOI: 10.1364/OL.38.001149.

45. Serafimovich PG. Two-component nanocavity based on a regular photonic crystal nanobeam. Computer Optics, 2013; 37(2): 155-159.

46. Kazanskiy NL, Serafimovich PG. Using photonic crystal nanobeam cavities for integration of optical signal. Computer Optics, 2014; 38(2): 181-187.

47. Serafimovich PG, Kazanskiy NL, Khonina SN. Sandwich-typed resonator cavity based on a regular photonic crystal nanobeam. Journal of Physics: Conference Series, 2014; 490: 012167. DOI: $10.1088 / 1742-6596 / 490 / 1 / 012167$.

48. Kazanskiy NL, Serafimovich PG. Coupled-resonator optical wave-guides for temporal integration of optical signals. Optics Express, 2014; 22(11): 14004-14013. DOI: 10.1364/OE.22.014004.

49. Serafimovich PG, Kazanskiy NL. Active photonic crystal cavities for optical signal integration. Optical Memory and Neural Networks, 2015; 24(4): 260-271. DOI: 10.3103/S1060992X15040050.

50. Serafimovich PG, Kazanskiy NL. Compact multichannel spectrometer based on array of two-component photonic crystal cavities. Pattern Recognition and Image Analysis, 2015; 25(3): 526-531. DOI: 10.1134/S1054661815030219.

51. Kazanskiy NL, Serafimovich PG, Kharitonov SI, Abulkhanov SR. Nanocavity. RF patent for the invention 2513657 of 2012 , June 4. 
52. Egorov AV, Kazanskiy NL, Serafimovich PG. Using coupled photonic crystal cavities for increasing of sensor sensitivity. Computer Optics, 2015; 39(2): 158-162. DOI: 10.18287/0134-2452-2015-39-2-158-162.

53. Serafimovich PG. Optical Modulator Based on Coupled Photonic Crystal Cavities. Computer Optics, 2015; 39(2): 147-151.

54. Serafimovich PG. Use of coupled photonic crystal nanobeam cavities for temporal integration of optical signals. Proceedings of SPIE, 2015; 9533: 95330N. DOI: 10.1117/12.2180560.

55. Egorov AV, Kazanskiy NL, Serafimovich PG. Application of Photonic-Crystal Coupled Cavities for Increase in Sensitivity of Optical Sensor. Optical Memory and Neural Networks (Information Optics), 2016; 25(1): 25-31. DOI: 10.3103/S1060992X16010033.

56. Serafimovich PG, Kazanskiy NL. Optical modulator based on coupled photonic crystal cavities. Journal of Modern Optics, 2016; 63(13): 1233-1238. DOI: 10.1080/09500340.2015.1135258.

57. Serafimovich PG, Stepikhova MV, Kazanskiy NL, Gusev SA, Egorov AV, Skorokhodov EV, Krasilnik ZF. On a silicon-based photonic-crystal cavity for the near-IR region: numerical simulation and formation technology. Semiconductors, 2016; 50(8): 1112-1116. 